\title{
Histopathologic Evaluation of Intralabyrinthine Schwannoma
}

\author{
Michael Bagattini ${ }^{a, b} \quad$ Alicia M. Quesnel ${ }^{c, d}$ Christof Rööslia, b \\ aDepartment of Otorhinolaryngology, Head and Neck Surgery, University Hospital Zurich, Zurich, Switzerland; \\ bDepartment of Otorhinolaryngology, Head and Neck Surgery, University of Zurich, Zurich, Switzerland; \\ 'Department of Otolaryngology-Head and Neck Surgery, Massachusetts Eye and Ear, Boston, MA, USA; ${ }^{\mathrm{d} D e p a r t m e n t}$ \\ of Otolaryngology-Head and Neck Surgery, Harvard Medical School, Boston, MA, USA
}

\section{Keywords}

Intralabyrinthine schwannoma - Vestibular schwannoma .

Histopathology · Cochlear implant

\begin{abstract}
Objectives: The aim of this study is to perform a histopathologic analysis of temporal bones with an intralabyrinthine schwannoma (ILS) in order to characterize its extension. Methods: Archival temporal bones with a diagnosis of sporadic schwannoma were identified. Both symptomatic and occult nonoperated ILS were included for further analysis. Results: A total of 6 ILS were identified, with 4 intracochlear and 2 intravestibular schwannomas. All intracochlear schwannomas involved the osseous spiral lamina, with 2 extending into the modiolus. The intravestibular schwannomas were limited to the vestibule, but growth into the bone next to the crista of the lateral semicircular canal was observed in 1 patient. Conclusions: Complete removal of an ILS may require partial removal of the modiolus or bone surrounding the crista ampullaris as an ILS may extend into these structures, risking damage of the neuronal structures. Due to the slow growth of the ILS, it remains unclear if a complete resection is required with the risk of destroying neural structures hindering hearing rehabilitation with a cochlear implant.

(C) 2020 The Author(s)

Published by S. Karger AG, Basel
\end{abstract}

\section{Introduction}

The incidence of vestibular schwannoma (VS) is rising and reaches 5/100,000 among all age groups, probably due to improved disease awareness, more widespread screening protocols for asymmetric hearing loss, increasing access to high-resolution MRI, and other yet unidentified contributors [Marinelli et al., 2020]. A VS may originate anywhere along the course of the vestibulocochlear nerve lateral to the glial-Schwann cell junction [Roosli et al., 2012]. The afferent fibers of the cochlear nerve run from the organ of Corti through multiple small openings (habenula perforata) along the basilar membrane to the spiral ganglia located in numerous bony canals of the modiolus, the Rosenthal's canal [Rosenthal, 1823]. When the tumor arises from a nerve sheath within the bony labyrinth, it results in an intralabyrinthine schwannoma (ILS). These tumors were only rarely detected previously with 23 cases described in the literature until 1988 [Sataloff et al., 1988]. They were diagnosed accidently during labyrinthectomy [Miyamoto et al., 1980; Hawke et al., 1981; Vernick et al., 1984; Huang, 1986], during the eighth nerve section surgery [Sataloff et al., 1988] or single case descriptions of postmortem during histopathologic examinations [Jorgensen, 1962; Perez De Moura et al., 1969; Gussen, 1971; Hoshino and Ishii, 1972; Thomsen and Jorgensen, 1973; Babin and Harker, 1980; Johns- karger@karger.com www.karger.com/aud

Karger $\stackrel{\text { ' }}{5}$

GOPEN ACCESS
(C) 2020 The Author(s)

Published by S. Karger AG, Basel

This is an Open Access article licensed under the Creative Commons Attribution-NonCommercial-4.0 International License (CC BY-NC) (http://www.karger.com/Services/OpenAccessLicense), applicable to the online version of the article only. Usage and distribution for commercial purposes requires written permission.
Christof Röösli

Department of Otorhinolaryngology, Head and Neck Surgery

University Hospital Zürich, Frauenklinikstrasse 24

CH-8091 Zurich (Switzerland)

Christof.Roeoesli@usz.ch 
Table 1. Patient characteristics

\begin{tabular}{|c|c|c|c|c|c|c|c|}
\hline $\mathrm{F}$ & 94 & Left & $\begin{array}{l}\text { Bilateral progressive sensorineural hearing } \\
\text { loss (beginning at age } 30 \mathrm{yr} \text { ) }\end{array}$ & $\begin{array}{l}\text { Intermittent episodes of } \\
\text { vertigo }\end{array}$ & Yes & $\begin{array}{l}\text { Cochlea, middle } \\
\text { turn }\end{array}$ & $\begin{array}{l}\text { Osseous basilar lamina } \\
\text { Scala tympani }\end{array}$ \\
\hline M & 88 & Right & $\begin{array}{l}\text { Severe noise trauma during WWII. } \\
\text { Left ear: deaf at age } 26 \text {; CI with } 71 \mathrm{yr} \\
\text { Right ear: deaf at age } 70 . \text { CI at } 82 \mathrm{yr}\end{array}$ & $\begin{array}{l}\text { Several attacks of vertigo } \\
\text { from age } 23 \text { to } 30\end{array}$ & No & $\begin{array}{l}\text { Cochlea, basal } \\
\text { turn }\end{array}$ & $\begin{array}{l}\text { Osseous basilar lamina } \\
\text { Modiolus } \\
\text { Scala tympani } \\
\text { Scala vestibuli }\end{array}$ \\
\hline M & 80 & Right & $\begin{array}{l}\text { Bilateral progressive hearing loss (beginning } \\
\text { at } 12 \mathrm{yr} \text { ) }\end{array}$ & No & Yes & $\begin{array}{l}\text { Cochlea, apical } \\
\text { turn }\end{array}$ & $\begin{array}{l}\text { Osseous basilar lamina } \\
\text { Scala tympani }\end{array}$ \\
\hline $\mathrm{F}$ & 84 & Left & Bilateral deafness (at 22 months) & No & No & Vestibule & Utricle \\
\hline
\end{tabular}

ILS, intralabyrinthine schwannoma; SCC, semicircular canal; yr, years.

son and Kingsley, 1981; Ohtani et al., 1990]. In the last years, MRI has become widely available, and resolution increases and more advanced MRI sequences allow detection of small tumors down to $1 \mathrm{~mm}$. With this rapidly advancing technology, an increasing number of small ILS can be detected. More than 500 cases are described in the literature by 2019 [Choudhury et al., 2019]. The incidence of ILS is reported to exceed $1 / 100,000$ person-years [Marinelli et al., 2018]. The number of patients undergoing surgical resection for growing ILS is increasing. Simultaneous tumor removal and hearing rehabilitation by inserting a cochlear implant (CI) into the cochlea has become a beneficial option for patients. This option is possible, even if a large part of the (basal) cochlea needs to be opened [Plontke et al., 2017; Plontke et al., 2018]. Followup with regard to tumor growth of an ILS after CI is more complicated but described to be possible despite artifacts by the implanted electrode and magnet. The internal receiver needs to be placed in an exaggerated posterosuperior position [Carlson et al., 2015]. Therefore, the question arises of what structures are involved in the extension of ILS, as this may help to estimate the risk of continued growth. The aim of this study is to perform a histopathologic analysis of temporal bones with an ILS in order to characterize the tumor extension.

\section{Materials and Methods}

Archival temporal bones with a diagnosis of sporadic VS within the collections at the Massachusetts Eye and Ear Infirmary (MEEI) and the University Hospital of Zurich (USZ) were examined. Specimens with previous surgery for the VS were excluded from further analysis. The temporal bones had been processed for light microscopy using the standard method of fixation in formalin, decalcification using trichloroacetic acid or ethylenediaminetetraacetate, embedding in celloidin, serial sectioning in the horizontal plane at a section thickness of 20 microns, and staining of every tenth section using hematoxylin and eosin [Merchant, 2010a]. Both symptomatic and occult cases of ILS were included. Sections of each case were examined to determine the origin of the tumor, its precise location in the labyrinth, and its extension. The institutional review boards of our respective institutions approved the study.

\section{Results}

A total of 39 temporal bones with sporadic schwannomas were identified ( 33 from MEEI and 6 from USZ). An ILS was found in 6 temporal bones from 3 male and 3 female patients with a mean age of 83 years (range, 68-94 years). The patient characteristics are summarized in Table 1. All patients had a history of ear-related symptoms. The patient history and important histologic findings are described below. 


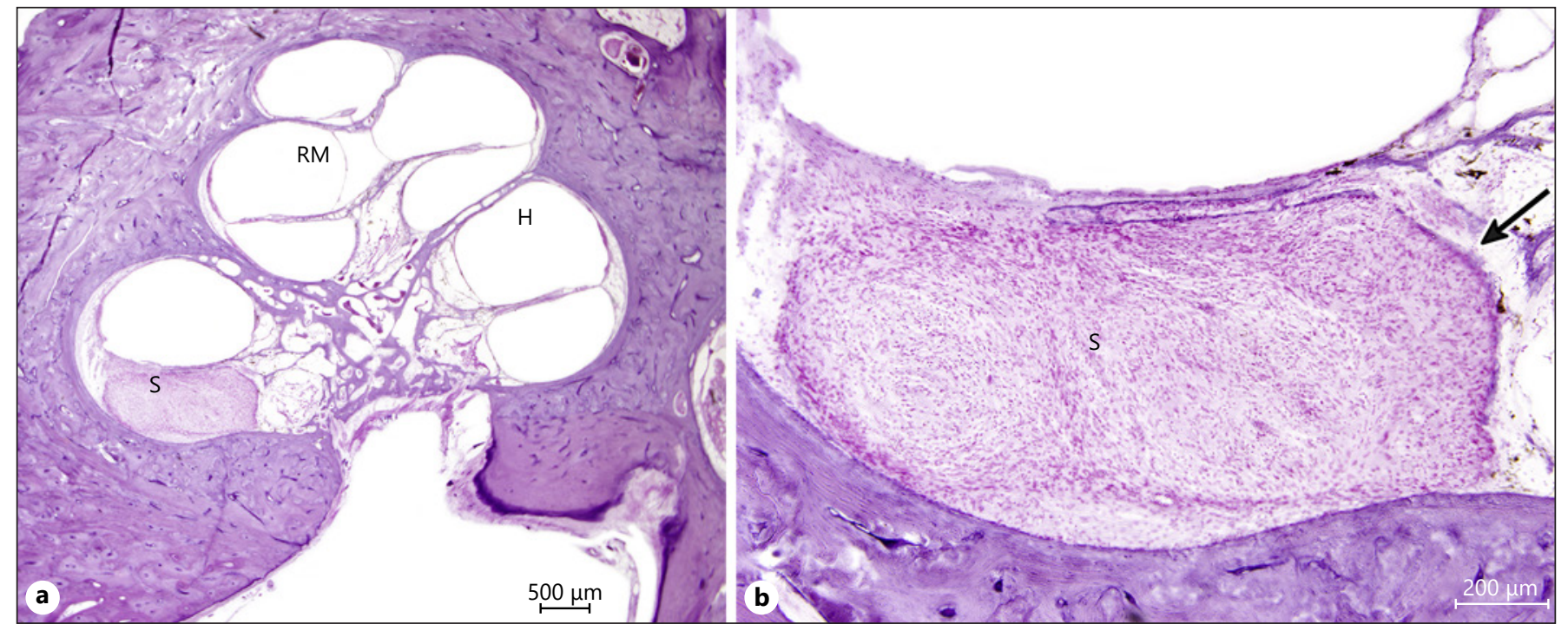

Fig. 1. a Schwannoma in the scala tympani of the basal turn of the cochlea. Endolymphatic hydrops is present. b The tumor extends through the osseous basilar lamina into the modiolus (arrow). S, schwannoma; H, hydrops; RM, Reissner membrane.
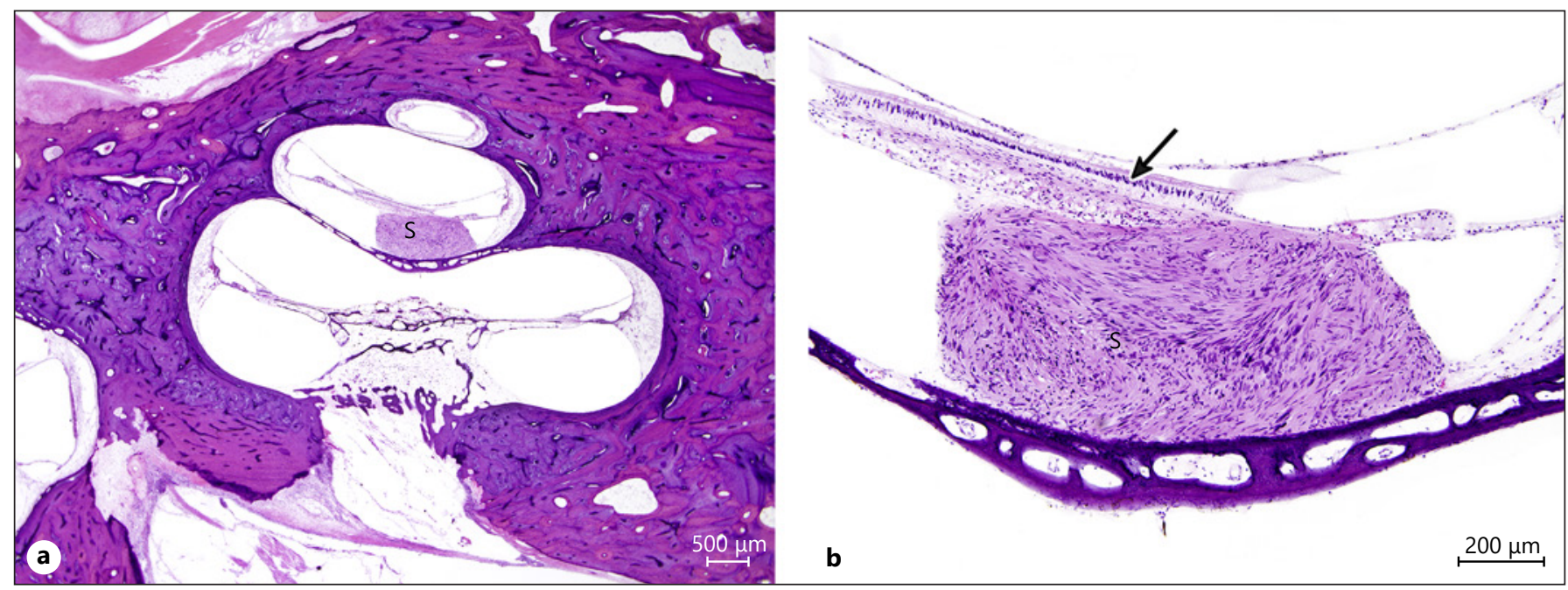

Fig. 2. a Schwannoma in the scala tympani of the middle turn of the cochlea. $\mathbf{b}$ The tumor extends into the osseous basilar lamina (arrow). S, schwannoma.

\section{Patient 1}

The patient was admitted to the hospital with a history of hearing loss, vertigo attacks, nausea, and vomiting at the age of 38 years. A caloric test showed profound changes, not further described. No additional information about the cochleovestibular symptoms is available. $\mathrm{He}$ died at the age of 84 years from pneumonia.

The histologic exam showed in the basal turn of the scala tympani a dense tumor mass composed of whorls of spindle-shaped cells and some areas with arrangement of palisading characteristics of the intracochlear schwannoma. The tumor extended through the osseous basilar lamina into the modiolus. Hydrops was present with ballooning of Reissner's membrane, especially in the apical turn, and also in the vestibule. The spiral ganglion cells were severely degenerated, and the organ of Corti was mostly absent. The stria vascularis had small areas of atrophy but mostly appeared normal (Fig. 1). 


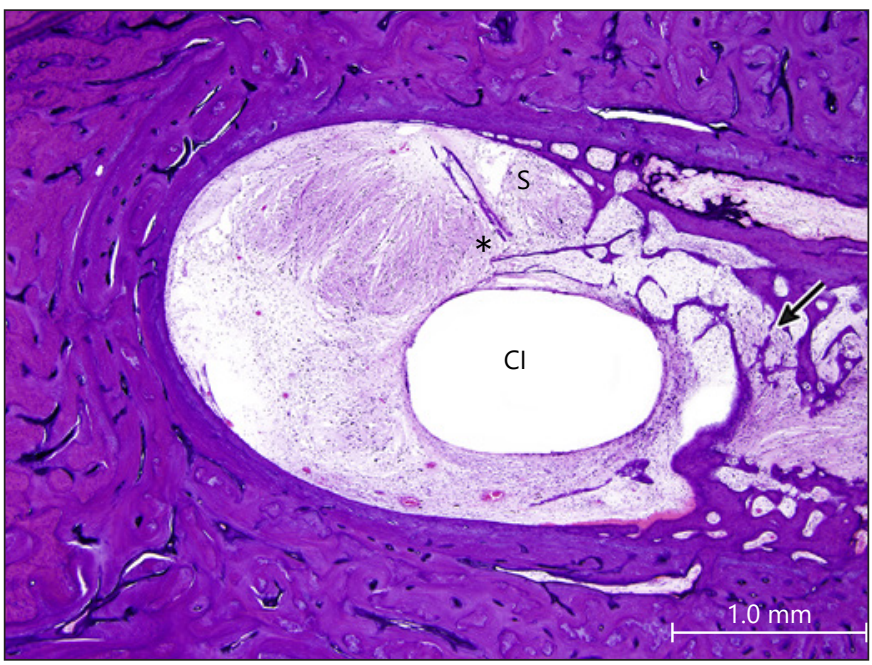

Fig. 3. Schwannoma completely fills the basal turn involving the scala tympani and vestibule and grows into the modiolus (arrow). The osseous basilar lamina is fractured $\left({ }^{*}\right)$. The former space of the $\mathrm{CI}$ electrode is surrounded by a fibrous tissue capsule. S, schwannoma; CI, cochlear implant.

\section{Patient 2}

The patient was previously described [Merchant, 2010b]. She developed a bilateral progressive sensorineural hearing loss at the age of 30 with tinnitus. She also had several intermittent episodes of mild to severe vertigo during her life. The patient died at the age of 94 from unknown causes.

The histologic exam showed a small intracochlear schwannoma in the scala tympani of the middle turn. The tumor appeared to arise from the osseous spiral lamina. The intracochlear schwannoma showed a high degree of cellularity consistent with Antoni type A. Hydrops was present in the apical turn. The spiral ganglion cells showed a significant degree of loss, and the organ of Corti showed severe atrophy. There was nearly complete atrophy of the stria vascularis (Fig. 2). A second small VS was located in the inferior vestibular nerve distal to Scarpa's ganglion with no connection to the intracochlear schwannoma.

\section{Patient 3}

The patient suffered from severe noise trauma during WWII. Profound deafness was diagnosed at age 26 on the left ear as well as an impaired hearing on the right ear. He had several attacks of vertigo from age 23 for 7 years. At the age of 71, he underwent cochlear implantation on the left, and at the age of 82 on the right side. A preoperative CT scan showed unremarkable appearing right temporal bone structures. During surgery, a gelatinous material

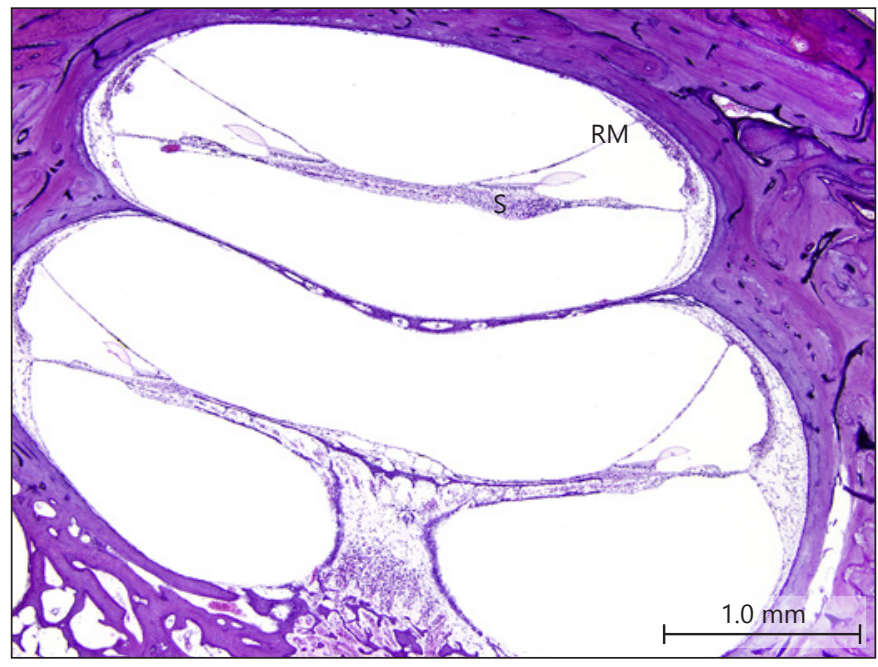

Fig. 4. A small schwannoma in the apical turn extending into the osseous basilar lamina. S, schwannoma; RM, Reissner membrane.

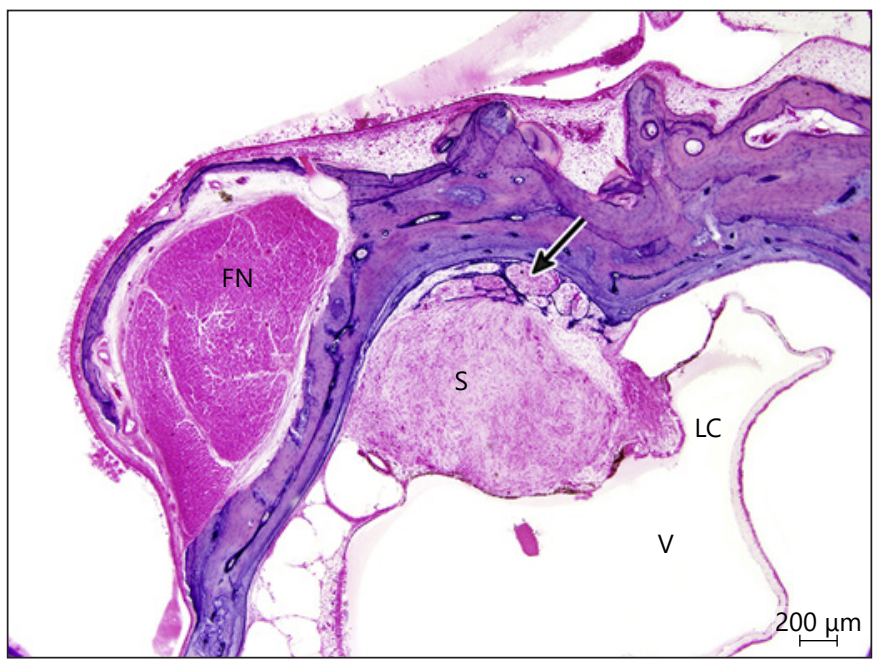

Fig. 5. A small schwannoma in the crista of the LC of the semicircular canal growing into the surrounding osseous structures (arrow). S, schwannoma; V, vestibule; FN, facial nerve; LC, lateral crista.

was found in the right cochlea. Incomplete insertion was accomplished with 4 electrodes remaining outside of the cochlea. He died of a heart attack at the age of 88 years.

The histologic exam showed the CI in the scala tympani. A dense fibrous sheath along the CI track and moderate new bone formation were found in the scala tympani. In 


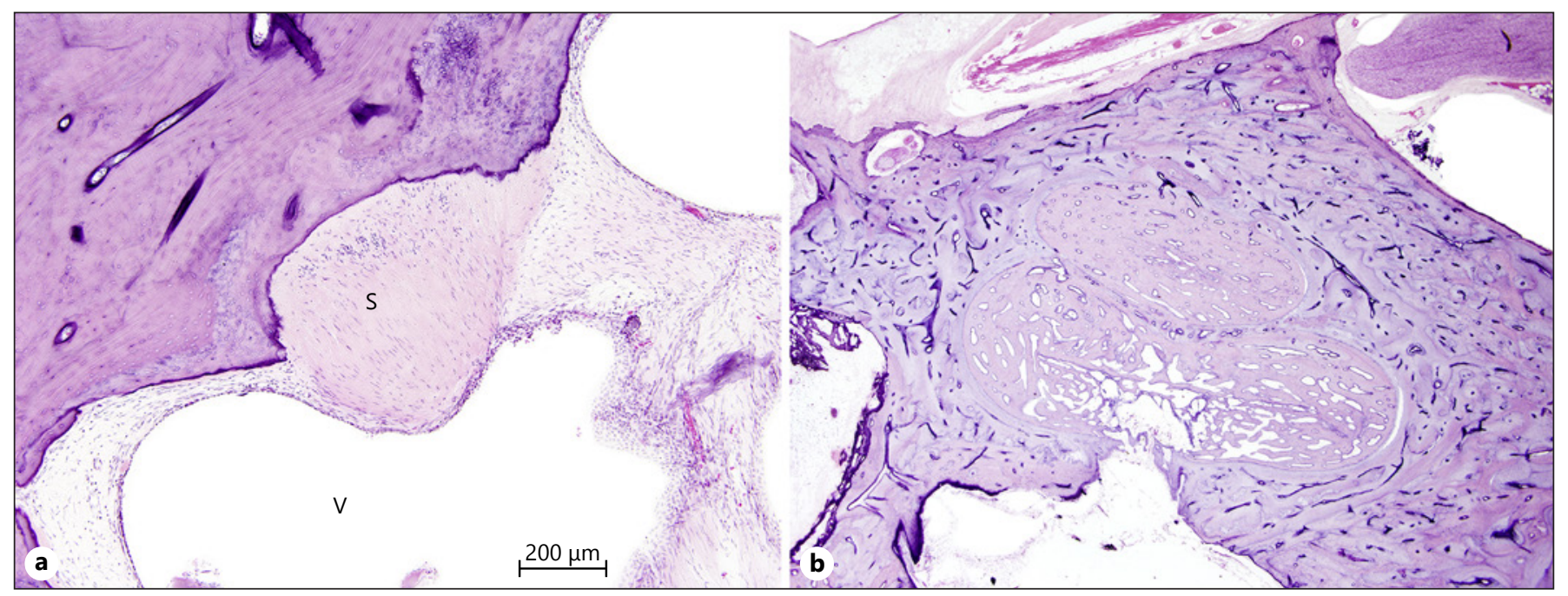

Fig. 6. a The palisading structure of cells indicate a small schwannoma in the vestibule. $\mathbf{b}$ The cochlea is completely ossified. S, schwannoma; V, vestibule.

the basal turn of the cochlea, the insertion process had fractured the osseous spiral lamina. A small intracochlear schwannoma was found in the basal turn in the scala tympani with extension through the osseous spiral lamina into the scala vestibuli reaching also the modiolus. The cells are spindle shaped. There was endolymphatic hydrops in all turns. The spiral ganglion cells were normal for age. The stria vascularis and the organ of Corti showed severe postmortem autolysis with no inner or outer hair cells (Fig. 3).

\section{Patient 4}

The patient developed a progressive hearing loss beginning at the age of 12 . He suffered from tinnitus for decades. He underwent CI surgery at the age of 72 on the left ear. He died at the age of 80 from an unknown cause.

The histologic exam showed a small intracochlear schwannoma originating in the osseous spiral lamina in the apical turn showing dense cellularity. No endolymphatic hydrops was found. The spiral ganglion cell count was normal for age. There was considerable atrophy of the stria vascularis in the basal turn and moderate atrophy in the middle and apical turns. The organ of Corti was reduced to a flattened epithelial layer in the basal turn and to an epithelial mound of cells in the middle turn. A few remaining outer and inner hair cells were found in the apical turn (Fig. 4).

\section{Patient 5}

This patient was previously described [Merchant, 2010c]. He suffered from an angiosarcoma of the nasal septum and right ethmoid region that was treated with local excision and intracavitary radium at the age of 20 . He developed mild sensorineural hearing loss, but no other cochleovestibular complaints were found. At the age of 68 , he died from meningoencephalitis caused by a CSF leak in the anterior skull base.

The histologic exam showed in the superior aspect of the perilymphatic space at the bases of the cristae of the lateral and superior semicircular canals a solid mass of cells with a whorled appearance, consistent with an intravestibular schwannoma. The crista of the lateral semicircular canal was invaded by the tumor, and the ampullary wall was reached, as are the cribrose areas. No endolymphatic hydrops was seen. The spiral ganglion cell count was slightly reduced. The stria vascularis appeared normal. The organ of Corti showed a loss of outer hair cells in the complete lower basal turn but was otherwise intact (Fig. 5).

\section{Patient 6}

The patient developed meningitis at the age of 22 months causing deafness. She died at the age of 84 from pancreatic cancer.

The histologic exam showed a small group of spindleshaped cells with the tendency toward palisading consistent with an intravestibular schwannoma (Fig. 6a). The cochlea (Fig. 6b) and all semicircular canal were completely obliterated by the bone with no cochlear structures remaining. The vestibule is not ossified. Some neurons remained in the basal turn. 
To summarize, the small intracochlear schwannomas have in common that the osseous spiral lamina is involved, and in 2 patients, an involvement of the modiolus was seen. For the intravestibular schwannomas, the tumors were limited to the vestibule, but growth into the bone next to the crista of the lateral semicircular canal was observed in 1 patient. Based on our findings, the exact site of origin cannot be determined. It remains unclear if an intracochlear schwannoma originates from the spiral lamina and grows into the modiolus or vice versa.

\section{Discussion}

The incidence of ILS is low, but increasing. A histopathologic evaluation of 7 patients with ILS by Santos et al. [2011] showed various changes of cochlear and vestibular structures that cause the symptoms. In our series, some patients have additional audiological diseases (such as noise trauma or cochlear ossification after meningitis) or underwent CI surgery. Therefore, it is challenging to determine the cause of the histopathologic findings and correlate these findings to the cochleovestibular symptoms.

While there is a clear propensity for VS in the internal auditory canal to originate from the vestibular nerve [Roosli et al. 2012], it seems to be less clear for ILS. The majority of reports found ILS more often in the cochlea [Dubernard et al., 2014; Marinelli et al., 2018], while others described an almost even distribution [Neff et al., 2003]. In our series, 4 ILS were found in the cochlea and 2 in the labyrinth. Due to the small number of cases described, it is difficult to draw any conclusions on the preferred location of tumor growth with regard to the cochlea or labyrinth. Histologic characteristics of ILS were previously described in patients after surgical removal [Plontke et al., 2017]. We did not find distinct histologic difference between ILS in the cochlea and labyrinth with the palisading characteristics of schwannoma in all patients.

Small tumors may be asymptomatic, and they can be adequately managed with serial MRI. Treatment is indicated for progressive tumor growth, progressive hearing loss, control of vertigo, or extension of the tumor into the internal auditory canal. Besides radiation therapy, different surgical techniques are described ranging from transotic tumor resection with middle ear obliteration and blind sac closure of the external auditory canal to transmastoid labyrinthectomy, to microscopic or endoscopic transcanal tumor resection with or without simultaneous
CI, to partial/subtotal cochleoectomy with simultaneous CI, or to CI without tumor removal (as in patient 3) [Carlson et al., 2015; Alicandri-Ciufelli et al., 2017; Mazzoni et al., 2017; Xia et al., 2017; Plontke et al., 2018; $\mathrm{Ma}$ and Patel, 2020]. The simultaneous resection of the ILS and placement of a CI shows promising results with regard to hearing rehabilitation despite opening of the cochlea [Plontke et al., 2020a]. A perimodiolar malleable electrode array may be beneficial for some patients [Plontke et al., 2020b]. However, the challenges include completeness of tumor resection [Ma and Patel, 2020], long-term tumor control, and follow-up. These challenges remain yet unresolved. The recurrence rate varies between studies and depends on follow-up time and completeness of tumor removal [Abouzari et al., 2020]. There are no data available for recurrence of ILS. Follow-up MRI for possible growth of residual ILS is challenged by artifacts of the magnet in the receiver coil and electrode contacts in case of the presence of a CI. It is possible to visualize the internal auditory canal and maybe even the modiolus where residual tumor is expected if the internal receiver is placed in an exaggerated posterosuperior position [Carlson et al., 2015]. Changes in the electrophysiological measurements of the CI such as the impedance [Plontke et al., 2017], electrically evoked compound action potentials, or changes of electrically evoked auditory brainstem response thresholds could indicate a tumor growth. However, the differentiation between fibrosis, new bone formation, or tumor growth is probably not trivial and maybe not possible by electrophysiological measurements alone. Tumor growth could also cause a decrease of hearing performance and speech understandability. Given the slow growth of schwannoma, it is possible that tumor growth does not affect patients' hearing ability. Clinical follow-up studies are required to answer the question of how often tumor growth in these patients occurs and if complete tumor removal for ILS is required. If complete removal of the ILS is aimed for, the approximate extension needs to be anticipated. Our findings indicate that tumor involves the osseous spiral lamina in the area of the tumor for intracochlear schwannoma and even the modiolar wall in some cases ( 2 out of 4 ). Resection of the modiolus, where spiral ganglion neurons reside, is associated with its destruction, preventing stimulation of neuronal structures with a CI, while even partial removal can lead to poor CI performance [Seyyedi et al., 2014]. Since the modiolus was not involved in 2 of the patients investigated in this study, subtotal resection could be considered in favor of achieving better chances for hearing rehabilitation with a CI. For intravestibular schwannoma, 
the ampulla of the affected semicircular canals is involved and needs to be drilled out resulting in a complete labyrinthectomy. The balance between complete tumor removal and neuronal structure preserving surgery is a challenge to the otologist. Since tumor location and extent vary considerably as do symptoms [Van Abel et al., 2013; Dubernard et al., 2014], the treatment goals need to be individualized on patient basis [Plontke et al., 2017]. Based on our study describing 6 patients, no generalization of treatment can be made due to the low number.

\section{Conclusion}

The study demonstrates that ILS may extend into the modiolus and the cristae of the semicircular canals. This histopathologic finding may have implications for the goal of achieving complete tumor resection while also optimizing hearing rehabilitation with a $\mathrm{CI}$ in these patients. Follow-up studies of patients with simultaneous removal of intracochlear schwannoma and CI will show how often growth of a persistent schwannoma impairs CI performance.

\section{Statement of Ethics}

The study was conducted in accordance with the World Medical Association Declaration of Helsinki. The institutional review boards of our respective institutions approved the study (KEK$\mathrm{ZH}-\mathrm{Nr}, 2015-0474$, and Massachusetts General Brigham IRB, 2020P000508).

\section{Conflict of Interest Statement}

The authors have declared that no conflicts of interest exist.

\section{Funding Sources}

This work was funded by a National Institute on Deafness and Other Communication Disorders, National Institutes of Health, grant (\#U24DC013983).

\section{Author Contributions}

M.B. and C.R. designed the work and examined and evaluated the histologic sections and patients' history. They analyzed the findings. All authors contributed to data interpretation, writing the manuscript, and gave approval to the version to be published.

\section{References}

Abouzari M, Goshtasbi K, Sarna B, Khosravi P, Reutershan T, Mostaghni N, et al. Prediction of vestibular schwannoma recurrence using artificial neural network. Laryngoscope Investig Otolaryngol. 2020;5(2):278-85.

Alicandri-Ciufelli M, Federici G, Anschuetz L, Pavesi G, Todeschini A, Presutti L, et al. Transcanal surgery for vestibular schwannomas: a pictorial review of radiological findings, surgical anatomy and comparison to the traditional translabyrinthine approach. Eur Arch Otorhinolaryngol. 2017;274(9):3295302.

Babin RW, Harker LA. Intralabyrinthine acoustic neurinomas. Otolaryngol Head Neck Surg. 1980;88(4):455-61.

Carlson ML, Neff BA, Link MJ, Lane JI, Watson $\mathrm{RE}, \mathrm{McGee} \mathrm{KP}$, et al. Magnetic resonance imaging with cochlear implant magnet in place: safety and imaging quality. Otol Neurotol. 2015;36(6):965-71.

Choudhury B, Carlson ML, Jethanamest D. Intralabyrinthine schwannomas: disease presentation, tumor management, and hearing rehabilitation. J Neurol Surg B Skull Base. 2019; 80(2):196-202.

Dubernard X, Somers T, Veros K, Vincent C, Franco-Vidal V, Deguine O, et al. Clinical presentation of intralabyrinthine schwannomas: a multicenter study of 110 cases. Otol Neurotol. 2014;35(9):1641-9.
Gussen R. Intramodiolar acoustic neurinoma. Laryngoscope. 1971;81(12):1979-84.

Hawke M, Keene M, Robbins KT, Fredrickson JM, Sima A. Occult intralabyrinthine schwannoma. J Otolaryngol. 1981;10(4):313-20.

Hoshino T, Ishii D. Intralabyrinthine neurilemmoma. A histopathological report. ORL J Otorhinolaryngol Relat Spec. 1972;34(2): $117-23$.

Huang TS. Primary intralabyrinthine schwannoma. Ann Otol Rhinol Laryngol. 1986;95(2 Pt 1):190-2.

Johnsson LG, Kingsley TC. Asymptomatic intracochlear neurinoma. A temporal bone report. Arch Otolaryngol. 1981;107(6):377-81.

Jorgensen MB. Intracochlear neurinoma. Acta Otolaryngol. 1962;54:227-32.

Ma AK, Patel N. Endoscope-assisted partial cochlectomy for intracochlear schwannoma with simultaneous cochlear implantation: a case report. Otol Neurotol. 2020 Mar;41(3): 334-8.

Marinelli JP, Lohse CM, Carlson ML. Incidence of intralabyrinthine schwannoma: a population-based study within the United States. Otol Neurotol. 2018;39(9):1191-4.

Marinelli JP, Lohse CM, Grossardt BR, Lane JI, Carlson ML. Rising incidence of sporadic vestibular schwannoma: true biological shift versus simply greater detection. Otol Neurotol. 2020 Jul;41(6):813-47.
Mazzoni A, Zanoletti E, Faccioli C, Martini A. Acoustic schwannoma with intracochlear extension and primary intracochlear schwannoma: removal through translabyrinthine approach with facial bridge cochleostomy and transcanal approach. Eur Arch Otorhinolaryngol. 2017;274(5):2149-54.

Merchant SN. Methods of removal, preparation and study. In: Merchant SN, Nadol JB, editors. Schuknecht's pathology of the ear. 3rd ed. Shelton: PMPH USA; 2010a. p. 3-51.

Merchant SN. Neoplastic growth. In: Merchant SN, Nadol JB, editors. Schuknecht's pathology of the ear. 3rd ed. Shelton: PMPH USA; 2010b. p. 496.

Merchant SN. Neoplastic growth. In: Merchant SN, Nadol JB, editors. Schuknecht's pathology of the ear. 3rd ed. Shelton: PMPH USA; 2010c. p. 503

Miyamoto RT, Isenberg SF, Culp WM, Tubergen LB. Isolated intralabyrinthine schwannoma. Am J Otol. 1980;1(4):215-7.

Neff BA, Willcox TO Jr, Sataloff RT. Intralabyrinthine schwannomas. Otol Neurotol. 2003; 24(2):299-307.

Ohtani I, Suzuki C, Aikawa T. Temporal bone pathology in intracochlear schwannoma with profound hearing loss. Auris Nasus Larynx. 1990;17(1):17-22. 
Perez De Moura LF, Hayden RC Jr, Conner GH. Further observations on acoustic neurinoma. Trans Am Acad Ophthalmol Otolaryngol. 1969;73(1):60-70.

Plontke SK, Rahne T, Pfister M, Götze G, Heider C, Pazaitis N, et al. Intralabyrinthine schwannomas: surgical management and hearing rehabilitation with cochlear implants. HNO. 2017;65(Suppl 2):136-48.

Plontke SK, Kösling S, Rahne T. Cochlear implantation after partial or subtotal cochleoectomy for intracochlear schwannoma removal: a technical report. Otol Neurotol. 2018;39(3): 365-71.

Plontke SK, Fröhlich L, Cozma S, Koitschev A, Reimann K, Weiß R, et al. Hearing rehabilitation after subtotal cochleoectomy using a new, perimodiolar malleable cochlear implant electrode array: a preliminary report. Eur Arch Otorhinolaryngol. 2020a Jun 5.
Plontke SK, Fröhlich L, Wagner L, Kösling S, Götze G, Siebolts U, et al. How much cochlea do you need for cochlear implantation? Otol Neurotol. 2020b Jun;41(5):694-703.

Roosli C, Linthicum FH Jr, Cureoglu S, Merchant $\mathrm{SN}$. What is the site of origin of cochleovestibular schwannomas? Audiol Neurootol. 2012;17(2):121-5.

Rosenthal F. Ueber den Bau der Spindel im menschlichen Ohr. In: Meckels archive. Berlin: Bd VIII; 1823.

Santos F, Linthicum FH, House JW, Wilkinson EP. Histopathologic markers of hearing loss in intralabyrinthine schwannomas: implications for management. Otol Neurotol. 2011; 32(9):1542-7.

Sataloff RT, Roberts BR, Feldman M. Intralabyrinthine schwannoma. Am J Otol. 1988;9(4): 323-6.
Seyyedi M, Viana LM, Nadol JB Jr. Within-subject comparison of word recognition and spiral ganglion cell count in bilateral cochlear implant recipients. Otol Neurotol. 2014 Sep; 35(8):1446-50.

Thomsen J, Jorgensen MB. Undiagnosed acoustic neurinomas. A presentation of 4 cases. Arch Klin Exp Ohren Nasen Kehlkopfheilkd. 1973; 204(3):175-82.

Van Abel KM, Carlson ML, Link MJ, Neff BA, Beatty CW, Lohse CM, et al. Primary inner ear schwannomas: a case series and systematic review of the literature. Laryngoscope. 2013;123(8):1957-66.

Vernick DM, Graham MD, McClatchey KD. Intralabyrinthine schwannoma. Laryngoscope. 1984;94(9):1241-3.

Xia Y, Zhang W, Li Y, Ma X, Liu Q, Shi J. The transotic approach for vestibular schwannoma: indications and results. Eur Arch Otorhinolaryngol. 2017;274(8):3041-7. 